\title{
New Insight into Atherosclerosis in Hemodialysis Patients: Overexpression of Scavenger Receptor and Macrophage Colony-Stimulating Factor Genes
}

\author{
Miki Nishida Minoru Ando Yusuke Iwamoto Ken Tsuchiya \\ Kosaku Nitta \\ Fourth Department of Internal Medicine, Tokyo Women's Medical University, Tokyo, Japan
}

\author{
Key Words \\ Cardiovascular disease $\cdot$ Colony-stimulating factor-1 receptor $\cdot$ Macrophage \\ colony-stimulating factor $\cdot$ Real-time reverse transcription polymerase chain reaction
}

\begin{abstract}
Background: Scavenger receptors (SRs) play a pivotal role in atherogenesis. The mechanism of atherosclerosis, which is specific to hemodialysis (HD) patients, was studied on the basis of SR gene expressions. Methods: The gene expressions of SR type A (SR-A) and CD36 were studied in peripheral monocytes by real-time reverse transcription polymerase chain reaction. Data were compared between HD $(n=30)$ and age-matched control subjects $(n=10)$. Serum levels of macrophage colony-stimulating factor (M-CSF) were measured with enzyme-linked immunosorbent assay to test its role in SR expression. The statistical differences and associations between two continuous variables were assessed using the Mann-Whitney $U$ test and Pearson's correlation coefficient, respectively. Results: The relative quantities of SR mRNAs were significantly greater in HD patients than in controls [median (interquartile range): SR-A, $1.67(0.96-2.76)$ vs. $0.90(0.60-1.04), p=0.0060 ; C D 36,1.09$ (0.88-1.74) vs. 0.74 (0.64-0.99), $\mathrm{p}=0.0255]$. The serum concentration of M-CSF was significantly higher in HD patients than in controls $[1,121(999-1,342)$ vs. $176(155-202) \mathrm{pg} / \mathrm{ml}, \mathrm{p}<0.0001]$. In addition, the relative quantity of M-CSF mRNA was significantly greater in HD patients than in controls [0.79 $(0.42-$ $1.53)$ vs. $0.42(0.28-0.66), p=0.0392]$. The serum $M-C S F$ levels were positively correlated with both the relative quantity of SR-A mRNA $\left(r^{2}=0.1681, p=0.0086\right)$ and that of CD36 mRNA $\left(r^{2}=0.1202, p=0.0284\right)$ in all subjects $(n=40)$. Conclusion: HD patients are predisposed to atherosclerosis as a consequence of their enhanced monocyte SR expressions. SRs and M-CSF are potential therapeutic targets for atherosclerosis in this high-risk population.
\end{abstract}


Nishida et al.: New Insight into Atherosclerosis in Hemodialysis Patients:

Overexpression of SR and M-CSF Genes

\section{Introduction}

Chronic kidney disease (CKD) is linked to an increased risk of atherosclerosis, and the prevalence and incidence of cardiovascular disease (CVD) in CKD patients are much higher than in the healthy population [1-4]. The increased CVD risk in CKD patients may be a consequence of hypertension (HTN) due to activation of the renin-angiotensin-aldosterone system [5], hypercalcification of vessels associated with abnormal metabolism of calcium and phosphorus $[6,7]$, the specific dyslipidemia of CKD, and so on [2, 8-10]. As far as hemodialysis (HD) patients are concerned, the following factors are also involved: activation of platelet aggregation due to shear stress in the extracorporeal circulation [11] and overproduction of inflammatory cytokines by lymphocytes or monocytes, possibly due to endotoxin contamination and contact with the dialysis membrane [12-14]. Although previous researchers have identified numerous clinical factors relevant to the development of atherosclerosis in CKD and HD patients, they have not studied the mechanisms of atherosclerosis that are specific to HD patients on the basis of molecular biology.

In the 1980s, Steinberg [15] described the oxidized low-density lipoprotein (ox-LDL) and scavenger receptor (SR) hypothesis, and Ross [16] proposed the vascular injury hypothesis. Both suggested that atherosclerosis is a chronic inflammatory disease that insidiously develops at the site of damaged endothelial cells. In the 1990s, Kodama et al. [17] cloned the SR gene, thereby establishing the molecular and cellular basis for the mechanism of atherosclerosis. The SRs are constitutively expressed in monocyte-macrophage lineage cells and have diverse functions, among which their involvement in atherosclerosis is of great importance. The receptors are classified into six major subtypes on the basis of their molecular structure and distribution in tissues. Among them, SR type A (SR-A) and CD36, which is a member of SR type B, play pivotal roles in the development of atherosclerosis. SR-A and CD36 in circulating monocytes phagocytose atherogenic ox-LDL in an unregulated manner, resulting in the formation of foam cells under the endothelium, which is thought to be the earliest stage of atherosclerosis $[15,16]$. Using SR-A knockout mice and dyslipidemic mice, Robbins et al. [18] showed that SR-A plays essential roles in both the phagocytosis of ox-LDL by macrophages and the development of atherosclerosis. Nevertheless, although the status of SR expression in circulating monocytes may provide us with new clues as to why atherosclerosis is accelerated in HD patients, this is not fully understood in the clinical setting.

We hypothesized that HD patients are predisposed to atherosclerosis at the molecular level, and we tested the hypothesis with special reference to SR expression in peripheral monocytes. In addition, we focused on the role of macrophage colony-stimulating factor (M-CSF), as several previous studies found that serum M-CSF concentration was greatly increased in CKD and HD patients [19, 20], and that the expression of SR in the human monocyte lineage cell line increased with increasing M-CSF concentration in the culture medium [21].

\section{Materials and Methods}

\section{Study Design}

This was a cross-sectional study. HD subjects were enrolled into the study at the time of routine outpatient care in Tokyo Women's University Hospital and Saito Memorial Hospital. Healthy control subjects were recruited from the staff of Tokyo Women's Medical University Hospital. The study was approved by the institutional review board of Tokyo Women's Medical University Hospital (certificate number 2753, Tokyo Women's Medical University) and conducted in accordance with the Declaration of Helsinki Principles on Human Experimentation. Informed consent was obtained from all subjects. 
Nishida et al.: New Insight into Atherosclerosis in Hemodialysis Patients:

Overexpression of SR and M-CSF Genes

\section{Blood Sampling and Laboratory Measurements}

Whole blood was collected in a container with EDTA-2 kalium (2 ml) for whole blood cell count and in a container with no anticoagulant agents $(10 \mathrm{ml})$ for other laboratory measurements at the start of HD or before breakfast in the morning. Four of these $10 \mathrm{ml}$ were immediately processed according to the manufacturer's instructions for the magnetically labeled Whole Blood CD14+ MicroBeads (Miltenyi Biotec, Cologne, Germany), and total RNA was extracted from the eluted CD14+ monocytes. The remaining blood was separated into serum and blood cells, and the serum was stored at $-80^{\circ} \mathrm{C}$ until assayed. Whole blood cell count and routine laboratory data were measured according to the conventional methods in the laboratory of Tokyo Women's Medical University. The electronic medical charts of all subjects were reviewed to determine the presence of comorbidities such as CKD, HTN, diabetes mellitus (DM), hyperlipidemia, and CVD. HTN was defined as a systolic blood pressure $\geq 140$ $\mathrm{mm} \mathrm{Hg}$ and/or a diastolic blood pressure $\geq 90 \mathrm{~mm} \mathrm{Hg}$, or use of antihypertensive agents at baseline. DM was defined as a diagnosis of DM prior to baseline, or the use of oral antidiabetic agents or insulin at baseline. Hyperlipidemia was defined as a serum total cholesterol concentration $\geq 230 \mathrm{mg} / \mathrm{dl}$ in the overnight fasting state. CVD included a past history of cerebral infarction, cerebral bleeding, ischemic heart disease, and peripheral vascular disease.

\section{Quantitative Real-Time Reverse Transcription Polymerase Chain Reaction (qRT-PCR)}

Total RNA was extracted from the CD14+ monocytes using ISOGEN (Wako Pure Chemical Industries, Tokyo, Japan) according to the manufacturer's instructions. Total RNA was determined by ultraviolet absorbance at $260 \mathrm{~nm}$. The purity of the isolated RNA was evaluated, measuring the ratio of absorbance at 260 and $280 \mathrm{~nm}$. RNA quality from each sample was assessed by measurement of the optical density $260 / 280$ ratio with a target optical density ratio $>1.7$. Extracted RNA from all samples was stored at $-80^{\circ} \mathrm{C}$. cDNA was generated from 300 ng of total RNA using an all-in-one kit and an RT ${ }^{2}$ First Strand Kit (Qiagen, Japan), and qRT-PCRs were performed in triplicate in 96-well plates with an AB 7500 Real-Time PCR system (Applied Biosystems, Foster City, Calif., USA) using RT ${ }^{2}$ SYBR Green qPCR Mastermix (Qiagen). Primers were purchased from SABiosciences for M-CSF (catalog number PPH00124B, product size 105 bp), C-FMS (CSF1R) (catalog number PPH00191F, product size 95 bp), SR-A (catalog number PPH01357, product size 76 bp), CD36 (catalog number PPH001356A, product size $121 \mathrm{bp}$ ), and glyceraldehyde 3-phosphate dehydrogenase (GAPDH) (catalog number PPH00150F, product size $175 \mathrm{bp}$ ). These primers were designed for SYBR Green qRT-PCR applications, and their experimentally verified design algorithm yielded gene-specific qRT-PCR assays. Amplification was conducted for 40 cycles $\left(95^{\circ} \mathrm{C}\right.$ for $30 \mathrm{~s}$ and $60^{\circ} \mathrm{C}$ for $60 \mathrm{~s}$ ), according to the manufacturer's instructions. M-CSF mRNA, C-FMS mRNA, SR-A mRNA, and CD36 mRNA expression levels in peripheral CD14+ monocytes were measured by qRT-PCR, using the comparative cycle threshold ( $\Delta \Delta \mathrm{Ct})$ method. GAPDH was chosen as an endogenous reference gene to adjust for variations in gene amplification efficiencies among samples, and thus a sample $\Delta \mathrm{Ct}$ (target gene $\mathrm{Ct}-\mathrm{GAPDH} \mathrm{Ct}$ ) was calculated (e.g., $2^{\text {sample SR-A Ct }} / 2^{\text {sample GAPDH Ct }}=2^{\text {sample SR-A Ct - GAPDH Ct }}=2^{\text {sample SR-A } \triangle C t}$ ). Next, the average of target gene $\Delta \mathrm{Cts}$ from 10 healthy samples was set as the calibration level of the target gene $\Delta \mathrm{Ct}$, and thus a sample $\Delta \Delta \mathrm{Ct}$ (sample target gene $\Delta \mathrm{Ct}$ - calibration $\Delta \mathrm{Ct}$ ) was calculated (e.g., $\left.2^{\text {sample SR-A } \Delta \mathrm{Ct}} / 2^{\text {calibration SR-A } \Delta \mathrm{Ct}}=2^{\text {sample SR-A } \Delta \mathrm{Ct} \text { - calibration } \Delta \mathrm{Ct}}=2^{\text {sample SR-A } \Delta \Delta \mathrm{Ct}}\right)$. This fold difference between the sample target gene $\Delta \mathrm{Ct}$ and the calibration $\Delta \mathrm{Ct}\left(-2^{\Delta \Delta \mathrm{Ct}}\right)$ was used as an index of relative target gene expression. The amplification efficiencies of M-CSF primer, C-FMS primer, SR-A primer, CD36 primer and GAPDH primer sets, which were confirmed to be approximately equal before the study, were analyzed using serial dilutions of RNA, as the equal amplification efficiencies of the target and endogenous reference mRNA allowed for the $\Delta \Delta$ Ct method [22-24]. 
Nishida et al.: New Insight into Atherosclerosis in Hemodialysis Patients:

Overexpression of SR and M-CSF Genes

\section{Measurement of Serum M-CSF Concentration}

The serum concentration of M-CSF was measured using commercially available quantitative sandwich enzyme-linked immunosorbent assay (ELISA) kits, following the manufacturer's standard protocol: Quantikine ELISA Human M-CSF Immunoassay (R\&D Systems, USA).

\section{Statistics}

Data were expressed as median and interquartile range, unless otherwise stated. Statistical analyses were performed using the Mann-Whitney $U$ test for continuous variables and the $\chi^{2}$ test for proportions. Common log transformation was applied when associations between the relative quantities of mRNA and the serum levels of M-CSF were assessed using Pearson's correlation coefficient, as those data were not normally distributed. All statistical analyses were performed using JMP 11 (SAS Institute Japan, Tokyo, Japan). All presented probability values are two-sided, and a p value $<0.05$ was considered to be statistically significant.

\section{Results}

\section{Demographic and Laboratory Data of HD Patients}

We studied 30 HD patients [14 men, 16 women; age 62 (55-67) years] and 10 control subjects [ 4 men, 6 women; age 60 (51-62) years]. The control subjects were age-matched and confirmed to have no CKD, DM, or CVD. The demographics and clinical characteristics of the chronic HD and control subjects are shown in table 1. HD duration was rather wide [67 (15-289) months], and the proportions of HD patients with DM or HTN were 26.7 and $73.3 \%$, respectively. HTN patients were taking one or some antihypertensive drugs, including angiotensin-converting enzyme inhibitors, angiotensin receptor blockers, and calcium channel blockers. Eleven (36.7\%) had been affected by CVD, including cerebral infarction, cerebral bleeding, ischemic heart disease, and peripheral vascular disease.

\section{SR-A and CD36 Gene Expressions in Peripheral Monocytes (qRT-PCR Analyses)}

The comparisons of the relative quantities of SR-A and CD36 mRNAs in peripheral CD14+ monocytes between HD and control subjects are shown in figures $1 \mathrm{a}$ and $\mathrm{b}$, respectively. SR-A gene expression was almost two-fold greater in the HD patients than in the controls [1.67 $(0.96-2.76)$ vs. $0.90(0.60-1.04), p=0.0060]$. CD36 gene expression was significantly greater in the HD patients than in the controls, but the group difference was smaller than that in SR-A gene expression [1.09 (0.88-1.74) vs. 0.74 (0.64-0.99), $p=0.0255]$.

\section{Serum M-CSF Concentration, and Gene Expressions of M-CSF and C-FMS in Peripheral Monocytes}

The serum concentration of M-CSF was nearly six-fold greater in the HD patients than in the controls [1,121 (999-1,342) vs. $176(155-202) \mathrm{pg} / \mathrm{ml}, \mathrm{p}<0.0001]$. The relative quantity of M-CSF mRNA was approximately two-fold greater in the HD patients than in the controls [0.79 (0.42-1.53) vs. $0.42(0.28-0.66), p=0.0392]$, whereas that of C-FMS mRNA did not differ between the HD and control subjects [0.71 (0.54-1.00) vs. $0.79(0.64-1.35), p=0.5220]$. These results are shown in figure 2 .

Correlations of Gene Expressions of Monocyte SRs and Serum M-CSF in Overall Samples

Among the overall (HD plus control) sample $(n=40)$, serum M-CSF concentration was significantly correlated with the relative quantity of SR-A mRNA $\left(r^{2}=0.168, p=0.0086\right)$ and with that of CD36 mRNA $\left(r^{2}=0.120, p=0.0284\right)$. These correlations are shown in figure 3 . In addition, serum M-CSF concentration was significantly associated with the relative quantity 
Nishida et al.: New Insight into Atherosclerosis in Hemodialysis Patients: Overexpression of SR and M-CSF Genes

Table 1. Demographics and laboratory data of the study subjects

\begin{tabular}{lcc}
\hline & HD patients & Controls \\
\hline Subjects & 30 & 10 \\
Men & $14(47 \%)$ & $4(40 \%)$ \\
Age, years & $62(55-67)$ & $60(51-62)$ \\
HD duration, months & $67(15-289)$ & - \\
DM & $8(27 \%)$ & $0(0 \%)$ \\
CVD & $11(37 \%)$ & $0(0 \%)$ \\
HTN & $22(73 \%)$ & $5(50 \%)$ \\
Use of ARB or ACEI & $19(63 \%)$ & $5(50 \%)$ \\
Use of calcium channel blocker & $16(53 \%)$ & $2(20 \%)$ \\
Use of statins & $17(57 \%)$ & $1(10 \%)$ \\
White blood cells, $\times 10^{3} / \mu \mathrm{l}$ & $5.17(4.07-6.71)$ & $5.12(4.37-5.88)$ \\
Red blood cells, $\times 10^{4} / \mu \mathrm{l}$ & $372(359-409)$ & $460(418-482)$ \\
Hemoglobin, g/dl & $10.8(10.4-11.6)$ & $13.6(13.2-14.4)$ \\
Hematocrit, $\%$ & $34.9(33.7-37.2)$ & $40.9(39.2-43.5)$ \\
Platelets, $\times 10^{4} / \mu l$ & $14.8(12.3-20.4)$ & $23.3(19.0-29.9)$ \\
Serum albumin, g/dl & $3.8(3.4-4.0)$ & $4.3(4.1-4.7)$ \\
Serum urea nitrogen, mg/dl & $65.0(53.0-71.8)$ & $17.1(11.2-18.5)$ \\
Serum creatinine, $\mathrm{mg} / \mathrm{dl}$ & $11.1(8.0-12.9)$ & $0.68(0.60-0.79)$ \\
Serum calcium, $\mathrm{mg} / \mathrm{dl}$ & $8.7(8.4-9.4)$ & $9.3(9.2-9.6)$ \\
Serum phosphorus, $\mathrm{mg} / \mathrm{dl}$ & $5.1(4.4-6.0)$ & $3.5(3.4-3.8)$ \\
Serum C-reactive $\mathrm{protein}, \mathrm{mg} / \mathrm{dl}$ & $0.09(0.05-0.14)$ & $0.04(0.04-0.09)$ \\
Serum total cholesterol, $\mathrm{mg} / \mathrm{dl}$ & $136(125-161)$ & $195(191-207)$ \\
Serum LDL-C, mg/dl & $67(55-80)$ & $713(94-129)$ \\
Serum HDL-C, mg/dl & $46(32-61)$ & $78(61-88)$ \\
Serum triglycerides, $\mathrm{mg} / \mathrm{dl}$ & $198(164-235)$ &
\end{tabular}

Data are expressed as n, n (\%), or median (interquartile range).

ACEI = Angiotensin-converting enzyme inhibitor; $\mathrm{ARB}=$ angiotensin receptor blocker; HDL-C = highdensity lipoprotein cholesterol; LDL-C = low-density lipoprotein cholesterol.

of M-CSF mRNA ( $\left.r^{2}=0.148, p=0.0142\right)$, but not with that of C-FMS mRNA $\left(r^{2}=4.727 \times 10^{-5}\right.$, $p=0.9664$ ). Moreover, there was a significant correlation between the relative quantities of SR-A and CD36 mRNAs $\left(r^{2}=0.142, p=0.0151\right)$.

\section{Discussion}

Our study has shown that the gene expressions of SR-A and CD36 in the peripheral monocytes of HD patients are enhanced in the resting state without any special extrinsic stimulation. In other words, this indicates that HD patients are more susceptible to atherosclerosis in the presence of increased concentrations of atherogenic lipoproteins such as ox-LDL $[25,26]$. Moreover, the study has shown that serum M-CSF concentration is extremely high in HD patients, raising the possibility that M-CSF plays a key role in stimulating monocyte SRs in HD patients.

Based on 'the SR and ox-LDL hypothesis' of Steinberg [15], the enhancement of monocyte SRs that we have observed in HD patients tends to support the notion that 'HD patients are predisposed to atherosclerosis'. Therefore, it is important to understand why monocyte SR gene expression is stimulated in such patients. Among the known stimulators of SRs, we focused on the role of M-CSF, as serum M-CSF levels are reported to be strongly increased in HD patients $[19,27]$. M-CSF is pertinent to the differentiation and growth of monocyte-macro- 


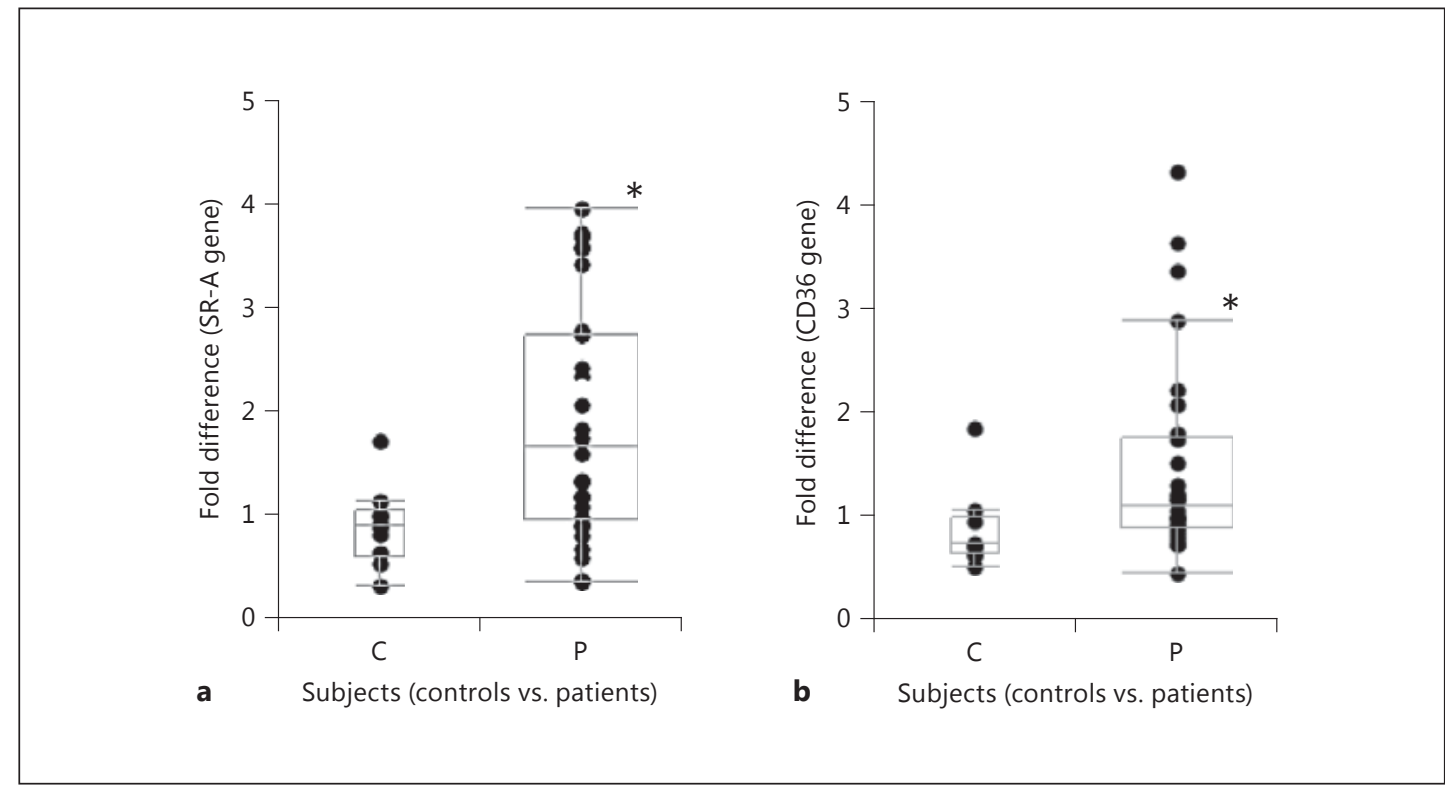

Fig. 1. Comparisons of the relative quantities of mRNA of SR-A (a) and CD36 (b). Data are visualized as boxand-whisker plots. Horizontal bars in boxes indicate median values and the height of boxes indicates the interquartile ranges of data. Error bars indicate standard deviations of data. Asterisks indicate that the differences between HD patients (P) and controls (C) are statistically significant $(\mathrm{p}<0.05)$. a The relative quantity of SR-A mRNA was significantly greater in the HD patients than in the controls. $\mathbf{b}$ The relative quantity of CD36 mRNA was significantly greater in the HD patients than in the controls.

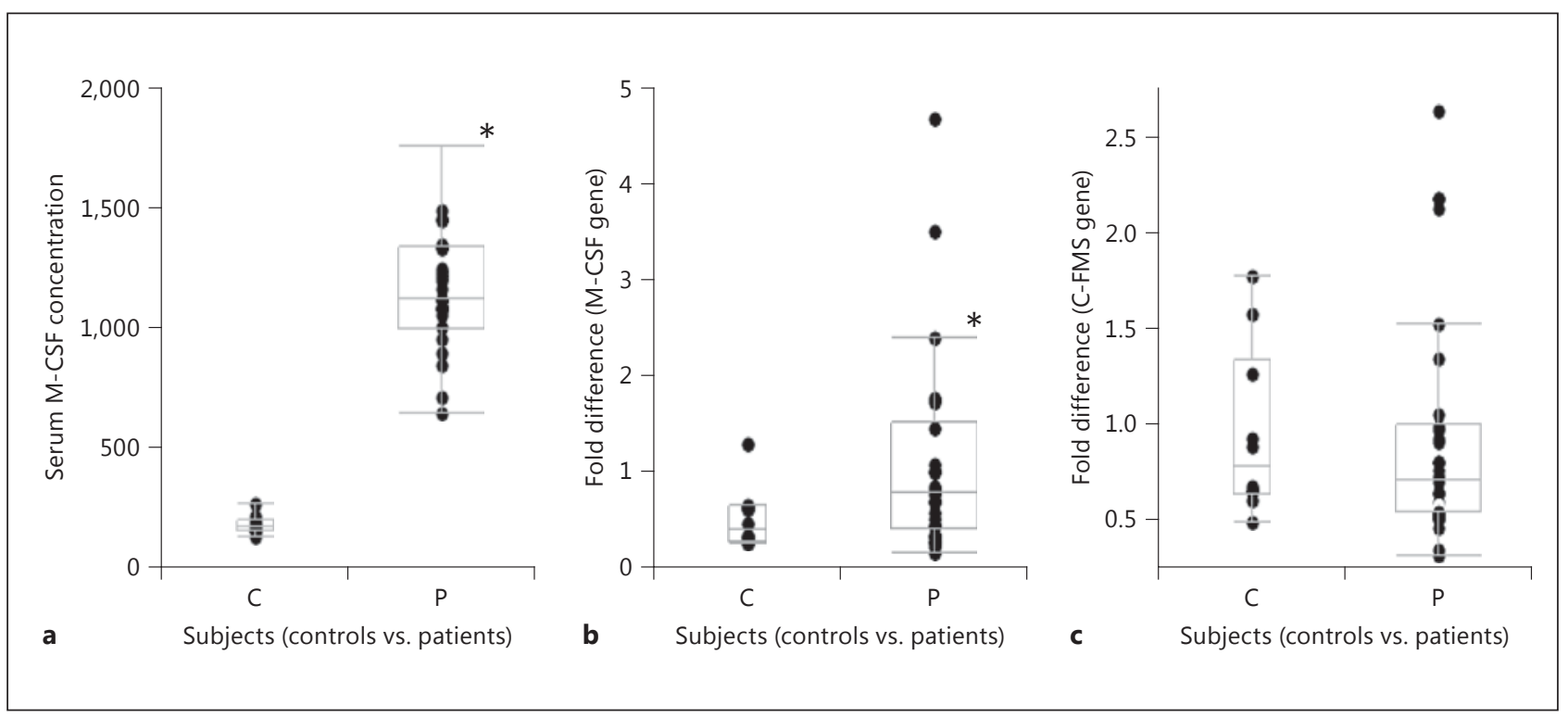

Fig. 2. Serum M-CSF level (a) and gene expressions of M-CSF (b) and C-FMS (c) in peripheral CD14+ monocytes. Data are visualized as box-and-whisker plots. Horizontal bars in boxes indicate median values and the height of boxes indicates the interquartile ranges of data. Error bars indicate standard deviations of data. Asterisks indicate that the differences between the HD patients (P) and controls (C) are statistically significant $(p<0.05)$. a Serum M-CSF concentration was significantly greater in the HD patients than in the controls. b, c The relative quantity of M-CSF mRNA was significantly greater in the HD patients than in the controls (b); however, that of C-FMS mRNA was not different between the HD and control subjects (c). 
Nishida et al:: New Insight into Atherosclerosis in Hemodialysis Patients: Overexpression of SR and M-CSF Genes

Fig. 3. Correlations of serum M-CSF concentration with gene expressions of SR-A (a) and CD36 (b). Common log transformation was applied in the correlation coefficient analysis, as the data were not normally distributed. Serum M-CSF concentration was significantly correlated with the relative quantities of SR-A mRNA (a; $\mathrm{r}^{2}=$ $0.168, \mathrm{p}=0.0086)$ and CD36 mRNA (b; $\mathrm{r}^{2}=0.122, \mathrm{p}=0.0284$ ) among the overall sample ( $\mathrm{n}=$ 40).

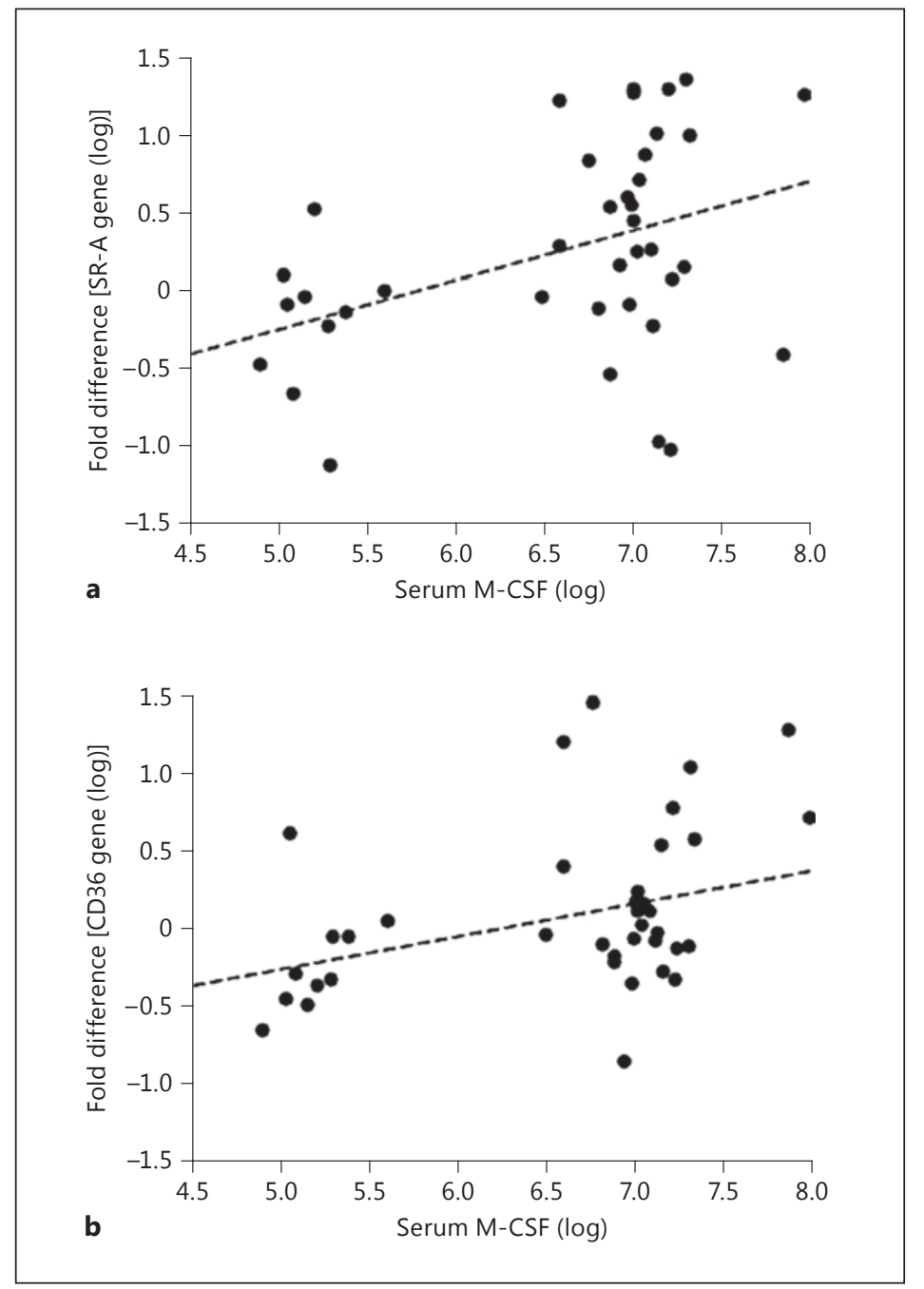

phage lineage cells, and therefore an excess of M-CSF may have the potential to cause SR overexpression in circulating monocytes. In vitro culture experiments using monocyte lineage cells have shown that the expression of the SR-A gene increased with increasing M-CSF concentration in the medium [21]. In fact, our present study showed that a higher concentration of serum M-CSF, which was possibly due to increased M-CSF gene expression in peripheral monocytes, was associated with increased SR gene expressions.

Why is serum M-CSF concentration so high in HD patients? First, M-CSF may accumulate in blood due to a decrease in urinary excretion. M-CSF forms a dimer of $85 \mathrm{kDa}$ molecular weight in the blood and is in part excreted into urine [28]. However, Le Meur et al. [20] found no difference in urinary M-CSF excretion between non-renal failure patients and renal failure patients with significantly elevated blood M-CSF levels, and they speculated that an alteration in urinary excretion is an unlikely cause of strongly increased M-CSF. Second, the abnormality of the specific receptor for M-CSF (C-FMS) in monocyte lineage cells needs to be considered. The major metabolic pathways of blood cytokines are mediated by binding to specific cytokine receptors in effector cells, a process that leads to their rapid removal from blood [29]. Nevertheless, this study did not show that peripheral monocyte C-FMS gene expression significantly decreased in the HD patients as compared with the control subjects. Third, overproduction of the M-CSF gene in monocyte lineage cells warrants discussion. M-CSF is produced primarily in 
monocyte-macrophage lineage cells, and in fact, we observed a significant increase in monocyte M-CSF gene expression in the HD patients compared with the controls. Although M-CSF gene expression is expected to be downregulated in HD patients due to their extremely high serum M-CSF levels, such downregulation appears to be disrupted. Taken together, intracellular regulation of the M-CSF gene may be defective in the monocytes of HD patients, which could be one of the causes (or consequences) of the high serum concentration of M-CSF.

Our study has several limitations. First, the sample size was small, the range of HD duration was rather wide, and the study population was limited to Japanese subjects. Therefore, in order to validate and generalize our results, it will be necessary to examine data from more HD and control subjects who have heterogeneity of ethnicity and homogeneity of HD duration. Second, monocyte heterogeneity, e.g., the three different monocyte subsets selected by CD14+, such as Mon 1 (CD14++CD16-CCR2+), Mon 2 (CD14++CD16+CCR2+), and Mon 3 (CD14+CD16++CCR2-), might be relevant to CKD-associated atherosclerosis [30], but it was not considered in this study. Third, characterization of M-CSF molecules was not studied. Profiling of M-CSF molecules accumulating in uremic serum on physical, chemical, and biological bases will be necessary in the future. Lastly, this study did not address how SR functions, such as phagocytic action of ox-LDL, are substantively increased in HD patients who manifest enhanced SR gene expressions. This is now under investigation in our laboratory, using ligand blot and flow cytometric analysis.

In conclusion, monocyte SR gene expressions are enhanced in HD patients in the resting state. M-CSF contributes to the enhancement of SR expressions, as both serum concentration and gene expression of M-CSF are significantly increased in HD patients. The abnormality of the SR gene expressions suggests that HD patients are susceptible to atherogenic lipoproteins such as ox-LDL, based on the currently established molecular mechanisms. Therefore, the attenuation of SR expressions in peripheral monocytes through the modulation of serum M-CSF levels is a likely therapeutic strategy for inhibiting the development of atherosclerosis in chronic HD patients. A prospective study is needed to clarify whether increased SR gene expression is a new risk factor linked to a higher incidence of CVD in HD patients.

\section{Acknowledgments}

We thank Dr. Kazunori Karasawa and Ms. Mayuko Hutaya of the Fourth Department of Internal Medicine, Tokyo Women's Medical University, for their valuable help.

\section{Disclosure Statement}

The authors declare no conflicts of interest.

\section{References}

1 Collado S, Coll E, Nicolau C, Pons M, Cruzado JM, Pascual J, Cases A: Carotid atherosclerotic disease predicts cardiovascular events in hemodialysis patients: a prospective study. PLoS One 2015;10:e127344.

-2 Gansevoort RT, Correa-Rotter R, Hemmelgarn BR, Jafar TH, Heerspink HJ, Mann JF, Matsushita K, Wen CP: Chronic kidney disease and cardiovascular risk: epidemiology, mechanisms, and prevention. Lancet 2013;27: 339-352.

3 Sarnak MJ, Levey AS, Schoolwerth AC, Coresh J, Culleton B, Hamm LL, McCullough PA, Kasiske BL, Kelepouris E, Klag MJ, Parfrey P, Pfeffer M, Raij L, Spinosa DJ, Wilson PW: Kidney disease as a risk factor for development of cardiovascular disease: a statement from the American Heart Association Councils on Kidney in Cardiovascular Disease, High Blood Pressure Research, Clinical Cardiology, and Epidemiology and Prevention. Circulation 2003;108:2154-2169. 
-4 Irie F, Iso H, Sairenchi T, Fukasawa N, Yamagishi K, Ikehara S, Kanashiki M, Saito Y, Ota H, Nose T: The relationships of proteinuria, serum creatinine, glomerular filtration rate with cardiovascular disease mortality in Japanese general population. Kidney Int 2006;69:1264-1271.

5 Campese VM, Park J: The kidney and hypertension: over 70 years of research. J Nephrol 2006;19:691-698.

6 Moe SM, Chen NX: Mechanisms of vascular calcification in chronic kidney disease. J Am Soc Nephrol 2008;19: 213-216.

7 Schoppet M, Shroff RC, Hofbauer LC, Shanahan CMM: Exploring the biology of vascular calcification in chronic kidney disease: what's circulating? Kidney Int 2008;73:384-390.

-8 Ikewaki K, Schaefer JR, Frischmann ME, Okubo K, Hosoya T, Mochizuki S, Dieplinger B, Trenkwalder E, Schweer H, Kronenberg F, Koenig P, Dieplinger H: Delayed in vivo catabolism of intermediate-density lipoprotein and low-density lipoprotein in hemodialysis patients as potential cause of premature atherosclerosis. Arterioscler Thromb Vasc Biol 2005;25:2615-2622.

-9 Kronenberg F, Konig P, Neyer U, Auinger M, Pribasnig A, Lang U, Reitinger J, Pinter G, Utermann G, Dieplinger $\mathrm{H}$ : Multicenter study of lipoprotein(a) and apolipoprotein(a) phenotypes in patients with end-stage renal disease treated by hemodialysis or continuous ambulatory peritoneal dialysis. J Am Soc Nephrol 1995;6:110 120.

10 Shoji T, Ishimura E, Inaba M, Tabata T, Nishizawa Y: Atherogenic lipoproteins in end-stage renal disease. Am J Kidney Dis 2001;38(4 suppl 1):S30-S33.

11 Ando M, Iwata A, Ozeki Y, Tsuchiya K, Akiba T, Nihei H: Circulating platelet-derived microparticles with procoagulant activity may be a potential cause of thrombosis in uremic patients. Kidney Int 2002;62:1757-1763.

-12 Takahashi T, Kubota M, Nakamura T, Ebihara I, Koide H: Interleukin-6 gene expression in peripheral blood mononuclear cells from patients undergoing hemodialysis or continuous ambulatory peritoneal dialysis. Ren Fail 2000;22:345-354.

13 Lonnemann G, Behme TC, Lenzner B, Floege J, Schulze M, Colton CK, Koch KM, Shaldon S: Permeability of dialyzer membranes to TNF alpha-inducing substances derived from water bacteria. Kidney Int 1992;42: 61-68.

-14 Yao Q, Lindholm B, Stenvinkel P: Inflammation as a cause of malnutrition, atherosclerotic cardiovascular disease, and poor outcome in hemodialysis patients. Hemodial Int 2004;8:118-129.

15 Steinberg D: The cholesterol controversy is over. Why did it take so long? Circulation 1989;80:1070-1078.

16 Ross R: Atherosclerosis - an inflammatory disease. N Engl J Med 1999;340:115-126.

17 Kodama T, Freeman M, Rohrer L, Zabrecky J, Matsudaira P, Krieger M: Type I macrophage scavenger receptor contains alpha-helical and collagen-like coiled coils. Nature 1990;343:531-535.

-18 Robbins CS, Hilgendorf I, Weber GF, Theurl I, Iwamoto Y, Fuqueiredo JL, Gorbatov R, Sukhova GK, Gerhardt LM, Smyth D, Zavitz CC, Shikatani EA, Parsons M, van Rooijen N, Lin HY, Husain M, Libby P, Nahrendorf M, Weisslender R, Swirski FK: Local proliferation dominates lesional macrophage accumulation in atherosclerosis. Nat Med 2013;19:1166-1172.

-19 Ando M, Lundkvist I, Bergstrom J, Lindholm B: Enhanced scavenger receptor expression in monocyte-macrophages in dialysis patients. Kidney Int 1996;49:773-780.

20 Le Meur Y, Fixe P, Aldigier JC, Leroux-Robert C, Praloran V: Macrophage colony stimulating factor involvement in uremic patients. Kidney Int 1996;50:1007-1012.

-21 Nikolic D, Calderon L, Du L, Post S: SR-A ligand and M-CSF dynamically regulate SR-A expression and function in primary macrophages via p38 MAPK activation. BMC Immunol 2011;12:37.

22 Espitia CM, Zhao W, Saldarriaga O, Osorio Y, Harrison LM, Cappello M, Travi BL, Melby PC: Duplex real-time reverse transcriptase PCR to determine cytokine mRNA expression in a hamster model of New World cutaneous leishmaniasis. BMC Immunol 2010;11:31.

-23 Livak KJ, Schmittgen TD: Analysis of relative gene expression data using real-time quantitative PCR and the $2^{-\Delta \Delta C \mathrm{t}}$ method. Methods 2001;25:402-408.

24 Schmittgen TD, Livak KJ: Analyzing real-time PCR data by the comparative $\mathrm{C}_{\mathrm{T}}$ method. Nat Protoc 2008;3: 1101-1108.

25 Maggi E, Bellazzi R, Falaschi F, Frattoni A, Perani G, Finardi G, Gazo A, Nai M, Romanini D, Bellomo G: Enhanced LDL oxidation in uremic patients: an additional mechanism for accelerated atherosclerosis? Kidney Int 1994; 45:876-883.

-26 Ando M, Sanaka T, Nihei H: Eicosapentanoic acid reduces plasma levels of remnant lipoproteins and prevents in vivo peroxidation of LDL in dialysis patients. J Am Soc Nephrol 1999;10:2177-2184.

-27 Ando M, Gafvels M, Bergstrom J, Lindholm B, Lundkvist I: Uremic serum enhances scavenger receptor expression and activity in the human monocytic cell line U937. Kidney Int 1997;51:785-792.

28 Motoyoshi K: Biological activities and clinical application of M-CSF. Int J Hematol 1998;67:109-122.

-29 Bezbradica JS, Medzhitov R: Integration of cytokine and heterologous receptor signaling pathways. Nat Immunol 2009;10:333-339.

-30 Rogacev KS, Seiler S, Zawada AM: CD14++CD16+ monocytes and cardiovascular outcome in patients with chronic kidney disease. Eur Heart J 2011;32:84-92. 